\title{
Oxygen solid electrolyte coulometry: Chances, challenges and new approaches
}

\author{
J. Zosel, A. Herms, J. Yao, M. Schelter, V. Vashook, U. Guth, M. Mertig \\ Kurt-Schwabe-Institut für Mess- und Sensortechnik e. V. Meinsberg, Kurt-Schwabe-Straße 4, \\ 04736 Waldheim, Germany \\ Jens Zosel (zosel@ksi-meinsberg.de)
}

\begin{abstract}
:
Oxygen solid electrolyte coulometry (OSEC) based on electrochemical cells made of yttria-stabilized zirconia (YSZ) is a long-standing method for gas sensing, material characterization as well as biological or medical measurements of oxygen exchange. Newer approaches are directed on analytical applications for chromatography or dissolved gas measurements. With optimized cell construction and operating conditions, the method enables the detection of gaseous quantities down to the picomolar range. The contribution gives an overview on the most important parameters, the characteristics and requirements regarding the sensors and also on actual developments.
\end{abstract}

Key words: oxygen solid electrolyte coulometry, yttria-stabilized zirconia (YSZ), oxygen partial pressure control, Faradaic and non-Faradaic current

\section{Introduction}

Oxygen solid electrolyte coulometry (OSEC) based on electrochemical cells made of yttria stabilized zirconia is a long-standing method used for gas sensing, material characterization as well as biological or medical measurements of oxygen exchange [1-4]. The method is based on the measurement of charges or currents for batch-like or flow-through titration of oxygen by a solid electrolyte cell based on the Faraday law. If the coulometric devices are equipped with measuring electrodes which support oxidation reactions in the gas phase by their high catalytic activity the method can also be applied for the Faradaic titration of oxidizable gases like hydrogen, carbon monoxide or hydrocarbons [5], if the oxygen concentration is near zero or fixed at a defined value.

Up to now most OSEC applications are directed on the measurement of gaseous quantities $>100 \mathrm{nmol}$ (batch coulometry) or concentrations $>100$ vol.-ppm (flow through coulometry). Applications in liquid coulometry show that this method can provide significantly lower limits of detection (LOD) down to the pmol range or ppb concentrations respectively. Therefore, this contribution is directed on the question on appropriate measures to decrease the LOD of OSEC significantly. Approaches for new appli- cations of flow-through coulometry are discussed as well.

\section{LOD influencing parameters}

In Fig. 1a the basic scheme of a commonly used YSZ cell for flow-through coulometry is shown. A downstream Nernst cell for controlling the desired oxygen partial pressure as the titration end-point (OTEP) is combined with an upstream cell for oxide ion pumping, which is driven galvanostatically. This setup has the disadvantage that oxygen partial pressures near the stoichiometric point $\left(\mathrm{pO}_{2} \approx 10^{-4}-1 \mathrm{~Pa}\right)$ cannot be established as OTEP due to oscillations of the control circuit. To adjust this $\mathrm{pO}_{2}$ range, which is very attractive to diminish the LOD of OSEC, the downstream measuring electrode is expendable and the pumping cell is controlled potentiostatically. This results in the simpler setup given in Fig. $1 \mathrm{~b}$. The LOD of this setup is influenced by the electronic conductivity of YSZ, the noise of the current measurement resulting from thermal oscillations, electromagnetic interferences (mostly from cell heating) and potential fluctuations of the potentiostatic control circuit. Optimizing all these influences, the LOD could be decreased down to an extend which enables the reliable titration of 100 ppb hydrogen in a nitrogen sample of $1 \mathrm{ml}$ after chromatographic separation [6]. 


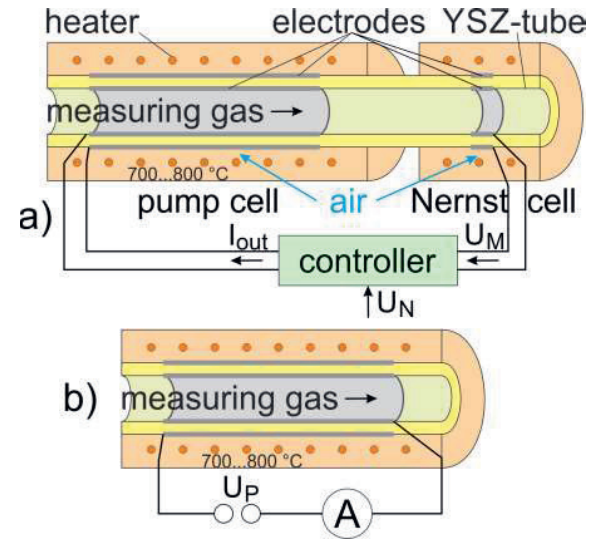

Fig. 1. Basic schemes of solid electrolyte cells used for OSEC, a): titration of larger concentrations with galvanostatically controlled pumping cell, b): titration of trace concentrations at an electrode with fixed potential.

\section{Results}

To quantify traces of oxygen or oxidizable gases exchanged during investigations on oxide ceramics, metals or other materials a setup according to Fig. 2 can be utilized. Here the $\mathrm{pO}_{2}$ of the dried gas $\left(\mathrm{N}_{2}\right.$ or $\left.\mathrm{Ar}\right)$ flowing into cell one is adjusted by applying a constant polarization $U_{P}$ versus an air reference electrode. Interactions between the gas and the sample result in $\mathrm{pO}_{2}$ changes. Cell two is used for titrating the gas coming from the heated sample by adjusting the same OTEP.

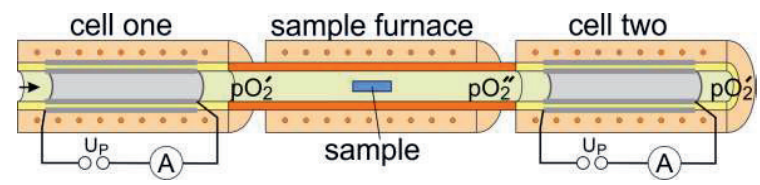

Fig. 2. Setup for coulometric measurement of oxygen exchange of heated samples.

A typical peak of the titration current measured in cell two after oxygen exchange of an YSZ sample is given in Fig. 3.

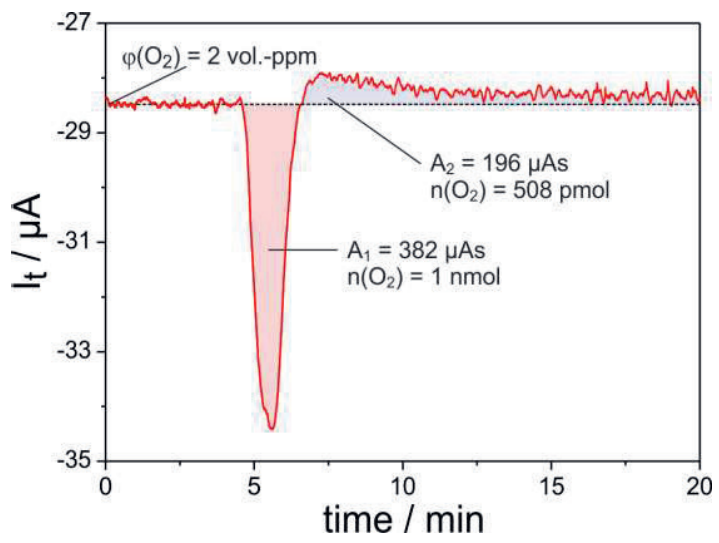

Fig. 3. Oxygen titration peak measured with cell two of the setup given in Fig. 2 at $U_{P}=-300 \mathrm{mV}$, sample $8 \mathrm{~mol}-\% \mathrm{YSZ}, \vartheta=650^{\circ} \mathrm{C}$, sample polarization $=25 \mathrm{mV}$, flow rate $=50 \mathrm{ml} / \mathrm{min}$.
The oxygen was released by the YSZ sample (dimensions $8 \times 5 \times 2 \mathrm{~mm}^{3}$ ) during a polarization with $25 \mathrm{mV}$ at two electrodes situated at the front-ends $5 \times 2 \mathrm{~mm}^{2}$. The oxygen partial pressure in the gas around the sample amounts to $6 \cdot 10^{-2} \mathrm{~Pa}$. The released oxygen is absorbed by the sample after the polarization again as indicated by the light blue area $A_{2}$ in Fig. 3 . The LOD in this setup was qualified to range below 100 pmol of exchanged oxygen. Fixing an oxygen slip during titration of $1 \%$ as the maximum tolerable error, the upper limit of the measurable titration current ranges above $5 \mathrm{~mA}$ at a flow rate of $50 \mathrm{ml} / \mathrm{min}$ through the setup. Assuming a titration time of 30 min the upper limit of detectable exchanged oxygen amounts accordingly to $25 \mu \mathrm{mol}$.

\section{Conclusion}

Knowledge on the influences of the coulometric cell construction, the material parameters of the solid electrolyte and other side conditions on the results of coulometric measurements enables precise titration of oxygen and oxidizable gases in the picomolar range.

\section{Acknowledgement}

Parts of the work are funded by the German Federal Ministry of Education and Research, project No. 03SF0542D. The authors are responsible for the content of the paper and gratefully acknowledge the funding.

\section{References}

[1] H. Ullmann, N. Trofimenko, Composition, structure and transport properties of perovskite-type oxides Solid State Ionics 119, 1-8 (1999); doi: 10.1016/S0167-2738(98)00474-3

[2] V. Vashook, J. Zosel, U. Guth, Oxygen solid electrolyte coulometry (OSEC) Journal of Solid State Electrochemistry 16, 3401-3421 (2012); doi: $10.1007 / \mathrm{s} 10008-012-1876-3$

[3] K. Teske, P. Popp, J. Baumbach, Solid-state coulometric cell as detector for gas chromatography Journal of Chromatography A 360, 417-420 (1986); doi: 10.1016/S0021-9673(00)91690-X

[4] J. Fouletier, G. Vitter, M. Kleitz, Measurement and regulation of oxygen content in gases using solid electrolyte cells. III. Oxygen pump-gauge Journal of Applied Electrochemistry 5, 111-120 (1975); doi: 10.1007/BF00613213

[5] M. Schelter, J. Zosel, W. Oelßner, M. Mertig, A novel method for measuring dissolved gases in liquids Sensors and Actuators B: Chemical 193, 113-120 (2014); doi: 10.1016/j.snb.2013.11.070

[6] M. Schelter, J. Zosel, V. Vashook, U. Guth, W. Oelßner, M. Mertig, Trace gas measurements with zirconia sensors: An overview proceedings of the $2^{\text {nd }}$ International Conference on Sensors Engineering and Electronics Instrumental Advances (SEIA' 2016) 